\title{
Comfort in the last 2 weeks of life: relationship to accessing palliative care services
}

\author{
David C. Currow • Alicia M. Ward • John L. Plummer • \\ Eduardo Bruera • Amy P. Abernethy
}

Received: 29 August 2007 / Accepted: 13 February 2008 / Published online: 12 March 2008

(C) The Author(s) 2008

\begin{abstract}
Introduction Specialised palliative care services (SPCS) aim to address the needs of patients and caregivers confronting life-limiting illnesses but only half of the potential cohort are referred. Randomised controlled trials of SPCS provision can no longer be ethically justified so there is a need to develop new methods to evaluate the net impact of SPCS for the whole community, not just for those who access SPCS. The aim of this study was to assess whether perceived comfort in the last 2 weeks of life was associated with accessing SPCS. Methods This study utilised a whole-of-population random survey $(n=4,366)$ in South Australia. A total of 802 respondents had someone close to them die within the last 5 years due to a terminal illness, and they had the complete
\end{abstract}

\section{C. Currow $(\bowtie) \cdot$ A. P. Abernethy}

Department of Palliative and Supportive Services,

Flinders University,

700 Goodwood Road, Daw Park,

Adelaide, South Australia 5041, Australia

e-mail: david.currow@rgh.sa.gov.au

A. M. Ward - A. P. Abernethy

Southern Adelaide Palliative Services,

Repatriation General Hospital,

Daw Park,

Adelaide, South Australia, Australia

\section{J. L. Plummer}

Department of Anaesthesia, Flinders Medical Centre,

Bedford Park,

Adelaide, South Australia, Australia

E. Bruera

Department of Palliative Care, MD Anderson Cancer Centre, Houston, TX, USA

\section{A. P. Abernethy}

Division of Medical Oncology, Department of Medicine,

Duke University Medical Centre,

Durham, NC, USA data. A subsequent question was asked whether SPCS had been accessed. Perceived comfort levels for those who had used SPCS were compared with those who did not by using stereotype logistic regression, weighted to a standardised population.

Results Higher levels of comfort of the deceased having been assessed 'very comfortable' was associated with the use of SPCS ( $p=0.04$; odds ratio, $1.78 ; 95 \%$ confidence interval, 1.02-3.08). For people who accessed SPCS, $13.3 \%$ were reported as 'very comfortable' compared with $8.0 \%$ without SPCS. Almost one half of respondents (48.4\%) reported that the deceased was considered 'uncomfortable' or 'very uncomfortable', irrespective of SPCS access.

Discussion While this study provides further incremental evidence of benefit from access to SPCS, there is much that still needs to be done to improve care for the whole community at the end of life.

Keywords Palliative care service access .

Population planning · Proxy reporting - Quality of care .

End-of-life care/terminal care/hospice care

\section{Introduction}

Patients and their family members identify comfort and good symptom control as essential components of good end-of-life care [21, 36, 47, 51, 53, 54]. Specialised palliative care services (SPCS) have developed to support a range of health professionals to address better the needs of patients and families confronting life-limiting illnesses. There is a need to understand all aspects of the benefits derived from SPCS access.

For patients, involvement of SPCS improve the "quality of dying" [55], pain assessment and management of people dying in nursing homes $[43,44]$ and symptomatic manage- 
ment in people admitted to hospital [26] and meet needs [54] and satisfaction with care [9, 28, 30]. For caregivers, SPCS involvement has been found to improve satisfaction $[28,54]$ and reduce anxiety [30]. In health service delivery, SPCS involvement reduced inpatient bed days $[9,12]$ and decreased costs when compared to conventional care without shortening prognosis $[9,52]$.

Systematic reviews of the impact of SPCS have been conducted and concluded that, while a benefit is suggested, data quality limits any conclusions [17-20, 24, 25]. Generally, studies have not been able to assess people with a life-limiting illness who have not accessed SPCS. Reasons for not utilising a service include a service not being available, declining involvement having been referred or because a referral was not made for this person to a service. Given that access rates to SPCS for people with a life-limiting illness are approximately $50 \%$ in developed nations, understanding what is happening to the $50 \%$ who do not access SPCS is pivotal to understanding better the net benefits of involving SPCS for service planning $[13,38]$.

Ethical concerns make it hard to justify health service level randomised controlled trials of SPCS involvement [17-20, $24,25]$. It is therefore imperative that other methods are used to compare the health outcomes of those who have and have not received input from SPCS. Comparing the experiences of these two groups may help to define additional benefits, problems or limitations conferred by accessing SPCS.

The South Australian Health Omnibus Survey has been utilised as a novel method to assess the palliative care needs of the population of South Australia $[49,13]$. The survey allows data to be collected from a cross-section of the South Australian population and, therefore, provides access to a systematically identified population of former caregivers of deceased individuals irrespective of SPCS involvement.

The aim of this study was to assess whether there was an association between levels of comfort in the terminal phase of a life-limiting illness and the use of SPCS. The null hypothesis was that there would be no difference in the proportion of people who were "very comfortable" in the last 2 weeks of life compared to those who had and had not accessed SPCS.

\section{Materials and methods}

The South Australian Health Omnibus [49] is an annual, random, face-to-face, cross-sectional survey conducted within the state of South Australia. It is administered by a commercial research organisation with government support. There is a cost for each question included in the survey. Respondents were asked if someone close to them had died of a terminal illness in the last 5 years in South Australia
(Table 1). Pilot testing of the questionnaire with 50 members of the general public for comprehension and usability occurred prior to administration and no changes were made to the wording as a result of piloting.

Table 1 South Australian Health Omnibus Survey 2004-palliative care questions relevant to comfort in the last 2 weeks of life

Palliative care questions

In the past 5 years, has anyone close to you in South Australia died of a terminal illness like cancer, motor neurone disease or emphysema? If yes, could you please say what their illness was? (Directions to interviewer-if more than one person has died, then ask about the person closest to the respondent)

- Cancer

- Motor neurone disease/multiple sclerosis

- Emphysema/other lung disease

- End-stage heart failure

- End-stage liver failure

- End-stage kidney failure

- HIV/AIDS

- Other (specify)

- Do not know illness

How long ago did this person die?

Where did this person die?

- Home

- Hospital

- Hospice

- Residential aged-care facility or nursing home

- Hostel

- Other

- Do not know

What was your relationship to this person?

- Spouse/partner

- Parent

- Child

- Sibling

- Other relative

- Friend

- Other (specify)

Consider the last 2 weeks of that person's life, was he/she comfortable?

- Very comfortable

- Comfortable

- Somewhat comfortable

- Somewhat uncomfortable

- Very uncomfortable

- Do not know

Did this person who died of a terminal illness use a palliative care service? (Definition provided - palliative care aims to comfort, not to cure, to relieve pain and distress for people who are dying and to support patients, families and friends in approaching death and coping with grief)

- Yes

- No

- Do not know 
Sampling schema

From September to December 2004, 4,500 households were approached. In metropolitan areas, a starting point was randomly selected for each Australian Bureau of Statistics collector's district, and then ten dwellings were randomly selected using a skip pattern of every fourth household. In non-metropolitan areas, households were selected using 100 starting points statewide; all towns with a population greater than 10,000 were included and towns with a population above 1,000 were randomly included. A cluster size of ten was used at each of the non-metropolitan starting points. One interview per household was conducted with the person over the age of 15 who had most recently had a birthday. Interviews were conducted face to face by trained interviewers. Prompt cards were provided for selected answers to allow responses to be categorised. Data were anonymous and were double punched. Any missing responses were followed up by a telephone call. For quality assurance, $10 \%$ of each interviewer's respondents were randomly selected and re-contacted to confirm eligibility and responses. These processes are applied to the whole survey, are unchanged since the survey's inception in 1991 and could not be modified just for the questions relating to the end of life.

\section{Setting}

South Australia has a population of 1.54 million people [8]. SPCS within South Australia span a range of different service delivery models, from large regional multidisciplinary teams within Adelaide to single clinical nurses in small rural locations. Each service covers a geographic region encompassing public and private hospitals (tertiary, district and free-standing palliative care units, outpatient clinics) and a community care team working in conjunction with general practitioners and community nurses. Almost $60 \%$ of people with a life-limiting illness are referred to SPCS in the state [13]. Nationally, the average time from referral to death is 102 days, with $28.5 \%$ of people accessing SPCS for longer than 6 months [6]. In this setting, services provide care in parallel with diseasemodifying therapies in line with World Health Organisation models [7].

\section{Statistical analysis}

Data were weighted according to the age, gender, geographic profile and country of birth using the 2001 standardised population of South Australia [8]. Descriptive statistics were used for respondent and patient characteristics. In analyses focusing on level of comfort, "very comfortable" was used as the reference point for outcomes.
The categorical responses to level of comfort in the last 2 weeks of life (Table 2) were analysed by stereotype logistic regression for both univariate and multivariate analyses [5]. The multi-factor model sought to exclude any confounding factors using the collected demographic data to explore differences in respondents' perceptions of comfort at the end of life by SPCS access. Stata software version 9.2 (Stata Corporation, 2005, College Station, TX, USA) was used for statistical analysis. A sensitivity analysis using data with unweighted data assessed the direction and magnitude of findings.

Ethics and consent

The Health Omnibus Survey received state ethics committee approval in 1991, and ethics review continues annually. Verbal consent was obtained from all participants (in South Australia, informed consent can be given by anyone over the age of 15).

\section{Results}

Description of respondents (unweighted)

A total of 4,500 households were approached to participate in the survey between September and December 2004. A participation rate of $76.0 \%$ was achieved (Fig. 1). There were a total of 1,465 male respondents (49.1\%) and 1,520 female respondents $(50.9 \%)$. Ages were evenly distributed. Three quarters $(75.5 \%)$ of the sample were born in Australia and $62.9 \%$ were married or in a de facto relationship.

Table 2 Reported level of comfort for individuals with a terminal illness in the last 2 weeks of life comparing by category of comfort for those who did and did not access a specialist palliative care service using data weighted to the standard population for key demographic characteristics

\begin{tabular}{|c|c|c|c|}
\hline Comfort level & $\begin{array}{l}\text { Total } \\
\text { sample }\end{array}$ & SPCS used & $\begin{array}{l}\text { SPCS not } \\
\text { used }\end{array}$ \\
\hline Very comfortable & $92(11.4 \%)$ & $69(13.3 \%)$ & $23(8.0 \%)$ \\
\hline Comfortable & $145(18.0 \%)$ & $94(18.0 \%)$ & $52(17.9 \%)$ \\
\hline $\begin{array}{l}\text { Somewhat } \\
\text { comfortable }\end{array}$ & $179(22.2 \%)$ & $111(21.3 \%)$ & $69(23.8 \%)$ \\
\hline $\begin{array}{l}\text { Somewhat } \\
\text { uncomfortable }\end{array}$ & $165(20.4 \%)$ & $106(20.4 \%)$ & $59(20.3 \%)$ \\
\hline Very uncomfortable & $228(28.1 \%)$ & $141(27.1 \%)$ & $86(30.0 \%)$ \\
\hline Total $^{\mathrm{a}}$ & $809(100 \%)$ & $521(100 \%)$ & $289(100 \%)$ \\
\hline
\end{tabular}

Respondents who did not know the person's level of comfort have been excluded $(n=59)$ and, additionally, those who did not know whether a palliative care service was used $(n=147)$. Twenty-eight people could not provide responses to either question.

${ }^{\text {a }}$ Numbers will not add up in rows or columns because populationweighted data have been used and rounded to the nearest integer for each cell. 
Fig. 1 The flowchart of engaging participants for the South Australian Health Omnibus 2004. Participation rate $76.0 \%$ $(2,985 / 3,927)$

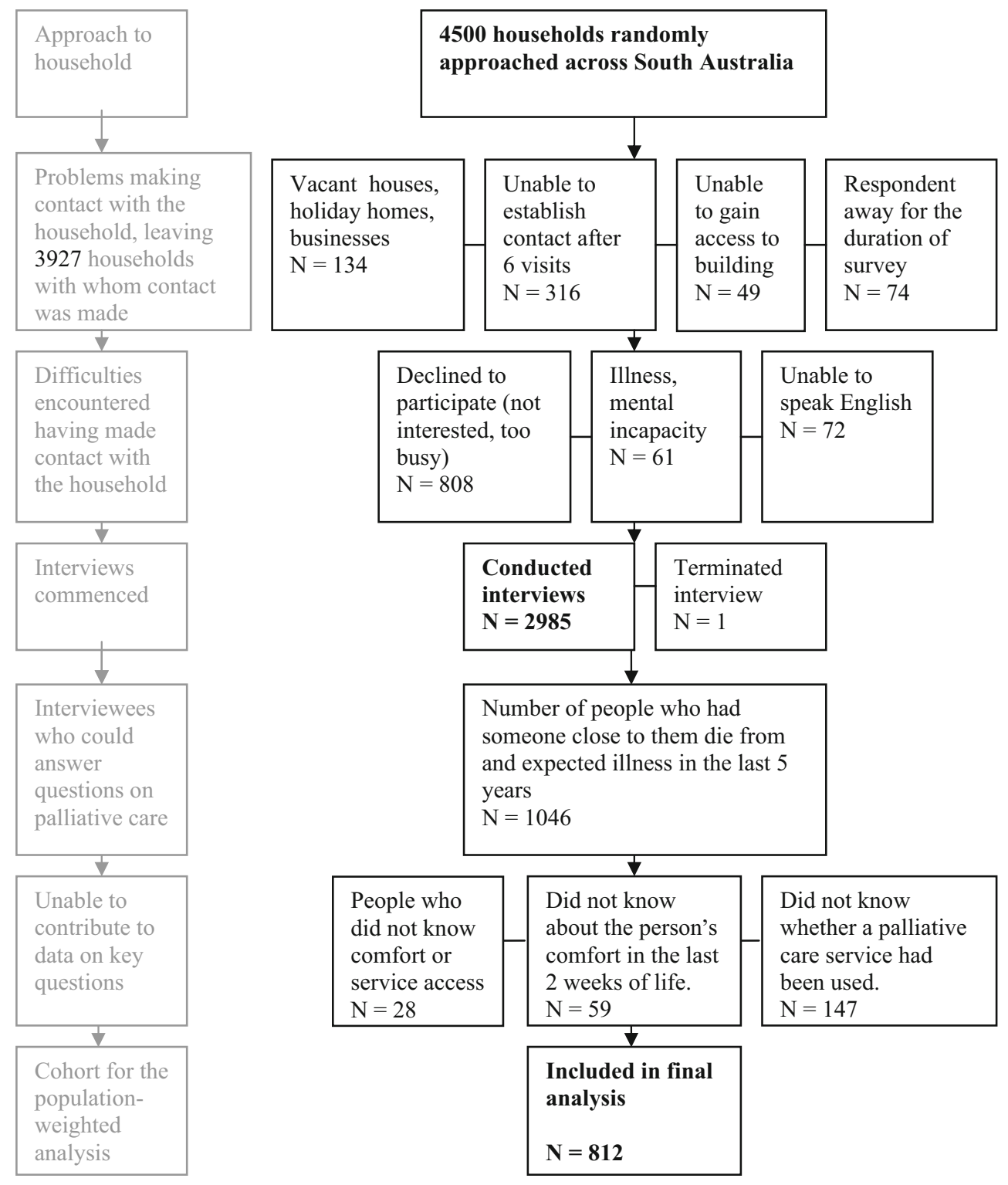

multi-factor analyses because they did not know the person's place of death.

Two key characteristics are available for the deceased person-diagnosis and age. The life-limiting illness was cancer for 668 people $(82.6 \%)$ and end-stage organ failure $(n=116)$, AIDS $(n=1)$ or motor neurone disease $(n=24)$ for others. The mean age of the deceased was 65.9 (range, 596; standard deviation (SD), 14.7).

The comfort level of the deceased in the last fortnight of life was rated as 'very comfortable' (11.4\%), 'comfortable' $(18.0 \%)$ or 'somewhat comfortable' (22.2\%) (Table 3). A total of $48.4 \%$ reported the person was uncomfortable in the last 2 weeks of life (20.3\% 'somewhat uncomfortable' and $28.1 \%$ 'very uncomfortable').

The association between the level of comfort and use of SPCS was examined in a multi-factor analysis by stereotype logistic regression having controlled for factors 
Table 3 Factors predictive of the deceased being 'very comfortable' in the last 2 weeks of life, as assessed by someone close to them up to 5 years after the death using population-weighted data and stereotype logistic regression $(n=802)$

Factors included in analysis

Demographic characteristics of the respondent

Demographic characteristics of the respondent that may change as the result of someone close to them dying

Factors associated with the person that died and their care

\begin{tabular}{|c|c|c|c|}
\hline Gender (male 359, female 438) & 0.65 & 0.88 & $0.51-1.53$ \\
\hline $\begin{array}{l}\text { Age (mean 48.3; SD 17.0) (15-29 (125), 30-44 } \\
(212), 45-59(261), 60-75(132),>75(67))\end{array}$ & 0.87 & & \\
\hline Country of birth (English speaking 722, other 76) & 0.43 & 1.41 & $0.60-3.31$ \\
\hline $\begin{array}{l}\text { Highest level of education (school only } 339 \text {, } \\
\text { higher education } 459 \text { ) }\end{array}$ & 0.76 & 0.92 & $0.55-1.55$ \\
\hline $\begin{array}{l}\text { Most involved level of care (any care 227, none } \\
\text { but still close to me 571) }\end{array}$ & 0.29 & 1.40 & $0.75-2.61$ \\
\hline $\begin{array}{l}\text { Marital status (married/de facto 559, separated/ } \\
\text { divorced } 70 \text {, widowed } 54 \text {, never married } 114 \text { ) }\end{array}$ & 0.23 & & \\
\hline $\begin{array}{l}\text { Work status (working/student 515, not working } \\
\text { 282) }\end{array}$ & 0.26 & 1.53 & $0.73-3.21$ \\
\hline $\begin{array}{l}\text { Income }(\times, 000 \text { per annum; }<20(142), 20-40 \\
(149), 41-60(135),>60(294) \text {, not stated }(77))\end{array}$ & 0.02 & & \\
\hline $\begin{array}{l}\text { Relationship to the deceased (spouse 32, other } \\
765 \text { ) }\end{array}$ & 0.78 & 0.86 & $0.30-2.50$ \\
\hline Diagnosis (cancer 660, non-cancer 137) & 0.50 & 1.32 & $0.59-2.93$ \\
\hline $\begin{array}{l}\text { Months since death (mean 23.4; SD 18.2) }(0-12 \\
(340), 13-24(175), 25-36(119),>36(164))\end{array}$ & 0.52 & & \\
\hline Use of palliative care service (yes 516, no 281) & 0.04 & 1.78 & $1.02-3.08$ \\
\hline Place of death (community 199, inpatient 598) & 1.11 & 0.90 & $0.61-2.01$ \\
\hline
\end{tabular}

relating to both the respondent and the deceased. The use of SPCS did not discriminate among the comfort levels of 'comfortable' to 'very uncomfortable'. The probability of the person being 'very comfortable' was significantly greater if SPCS was used ( $p=0.04$; odds ratio, $1.78 ; 95 \%$ confidence interval, 1.02 to 3.08 ). The only other factor that was significant was that fewer respondents in the higher income brackets $(6.2 \%$ in $\mathrm{A} \$ 40,000-60,000 ; 6.8 \%$ in $>\mathrm{A}$ $\$ 60,000)$ reported the level of comfort as "very comfortable" compared to those in lower brackets $(16.1 \%$ in $<\mathrm{A}$ $\$ 20,000 ; 15.9 \%$ in $\mathrm{A} \$ 20,000-40,000)$.

Sensitivity analysis

The raw survey data without population weightings were then completely re-analysed, confirming the direction and magnitude of each of these findings.

\section{Discussion}

What is new?

According to respondents, the use of SPCS was associated with higher levels of comfort during the last 2 weeks of life. This is the first study to assess the impact of SPCS on comfort in the last fortnight of life in a whole population using a random population survey method. Although the finding may seem intuitive, documenting this finding with the denominator as the community at large is new and crucial for service planning, contrasting with previous methodologies that have used mortality follow-back methods, contacted only caregivers known to a particular SPCS or employed secondary analyses to calculate "quality of death" scores [21, 36, 47, 51, 53-55]. After death, surveys can collect information on a representative sample of deaths rather than on just people who are able and willing to talk about their experiences [2] as was used in the Study to Understand Prognoses and Preferences for Outcomes and Risks of Treatment [36].

It is an overwhelming concern that one in two respondents indicated that someone close to them was 'uncomfortable' or 'very uncomfortable' in the terminal stage of life irrespective of whether SPCS was used or not. The nature of this lack of comfort is being explored in subsequent surveys to determine if it relates to physical or emotional symptoms, or both. Such a level of discomfort demands an urgent response by all service providers.

Are these statistically significant results also significant in clinical practice and health service planning given the proximity of the lower confidence interval to one? People with more complex symptoms are more likely to be referred 
to SPCS [14]. These are the same people who, in this study as they enter the terminal phase of their care, are ultimately reported to be more comfortable than people whose complexity of needs has not triggered a referral to SPCS. The net benefit of SPCS in contributing to comfort is therefore under-estimated in the statistical results. The modest magnitude of benefit seen in this study should be considered as an addition to the already existing evidence base for people who have accessed SPCS [15, 17-20, 24, 25]. The current study reflects only one time-limited facet of the overall contribution of SPCS to care - the terminal phase - and it is likely that the total benefit of accessing SPCS is the sum of benefits achieved by SPCS for patients, caregivers and health professionals over the entire period of contact.

Has perceived comfort differing across socio-economic strata been reported before? Although there are data that support differential access of SPCS by people from higher socio-economic strata $[1,3,13,23]$, this has not been linked to measured outcomes. The reason for such an association is not clear from the data currently available.

What are the strengths of the study?

This current study employs a new method to explore the impact of SPCS at a whole population level on a question central to continued funding of SPCS - do services make a difference to comfort at the end of life? The sampling process employed by the Health Omnibus allows a truly representative sample with the denominator being the whole population. Rather than using SPCS staff to survey perceptions of care and comfort, the use of independent interviewers reduced the likelihood of a biased positive appraisal.

Another strength of the study is the analysis tool. Initial analyses revealed that the assumptions underlying the proportional odds model were not met for level of comfort; hence, the less restrictive stereotype model was chosen. Reflecting the basic premise originally proposed by Anderson for stereotype logistic regression, the more commonly used proportional odds logistic regression was inappropriate to use in this study as the levels of comfort were not grouping an underlying continuous variable [5]. By contrast, stereotype logistic model should be used in cases in which respondents must choose between a number of ordered responses especially in a situation in which a predictor may discriminate between some but not all of the outcome categories.

Limitations-methods

This study used the reports of proxies to investigate the impact of SPCS on comfort at the end of life. Proxy reports are frequently used in palliative care research due to the difficulties encountered in research engaging people with a life-limiting illness $[2,4,11,31,33]$. Studies have examined the accuracy of retrospective reports by proxies, comparing reports of patients prior to death with those of their relatives after death $[4,10,22,27,31,33]$. In studies comparing concurrent prospective (pre-death) reports by patients and their relatives, family caregivers' overall symptom distress scores have been highly correlated with patients' overall scores [32, 35]. Families tend to rate symptoms more severely than patients [34, 37, 47] and under-report psychological distress [16, 34, 45]. Overall comfort is something that relatives can assess using several factors to reach their conclusions: levels of comfort stated by the patient $[48,50]$, behaviours, activity levels, analgesic use and facial expressions [40, 41]. All of these factors, potentially in a composite measure, should be included in future work seeking to understand levels of comfort at the end of life. Congruence between proxies and patients is greater for issues where there is an observable consequence [16], such as service utilisation, functional ability or preferred place of care [16, 22, 27, 31, 45]. Proxies living with patients have been found to have a higher level of agreement [39] but caregiver strain, unrealised expectations and poor caregiver coping may be associated with some incongruent reports [39, 42, 47] including reporting caregiver distress as patients' physical pain [47].

The current study is an important reflection of the people's perceptions of end-of-life care and is likely to relate to the deceased's experience. By the terminal phase of a life-limiting illness, individuals are often too unwell to participate even in initiatives designed to improve the quality of care. In this setting, proxies become an invaluable source of information about the quality and outcomes of the care given. Even if there are limitations in proxy reporting, family members' own perceptions demand attention [36]. Perspectives from all involved parties (patients, family, caregivers, clinical staff) should be sought in evaluating end-of-life care [33].

Counter-intuitively, even patients may not be "gold standard" reporters of discomfort as they may downplay or emphasise certain symptoms, not want to complain or seek to provide the answers they think are expected [2, 35, 39]. The "gold standard" of comfort is an amalgam from a number of key sources including patients and people close to them.

The timing of the interview and the way that questions are framed may have an impact on a bereaved person's proxy response about the deceased [39]. Concerns have been raised about the validity of retrospective proxy reports because respondents may be affected by grief or difficulties in recall. Many factors may influence the response to the question about the comfort of someone close who died 
including recall biases, positive reappraisal as a coping strategy and the net emotional effects of grief which may, at the time of answering, be positive or negative. The current study deliberately covers a large population and a 5-year period to account for some of the variations that may be encountered over time in reporting the comfort level of the deceased. To ensure that the net impact of time since death is taken into account when evaluating comfort in the last 2 weeks of life, time since death was included as a variable in the multi-factor analysis.

\section{Limitations-sample}

It is likely that certain groups including people whose first language was not English were under-represented in the raw data. Lower participation rates from identifiable subpopulations within the community are dealt with by using population-standardised weightings for all analyses. The study design meant that individuals in remote locations and patients without caregivers could not have their experiences reflected in the data.

Nearly a third of respondents who had experienced a death within 5 years reported the bereavement occurred within the last 12 months. In a population survey of this nature, deaths theoretically should be evenly distributed in each of the years across the 5-year period. This apparent anomaly may be due to recall error given that life-changing or highly emotional life events may feel more recent than they actually were $[2,11]$.

\section{Generalisability}

This report deals with responses from a single state, in a health system that has relatively high rates of access to SPCS. The models of care and care offered differ in health settings around the world and may therefore limit generalisability to health systems that are markedly different.

What are the implications for future research?

Future research in this area needs to validate these findings in different health systems. Rather than face-to-face interviews, computer-assisted telephone techniques could be used at a population level to replicate this study in other health systems. Given the annual nature of the Health Omnibus, the questions used in 2004 have been modified to allow assessment of physical comfort and distress separately in subsequent surveys $[29,46]$. Further research is also required to better understand the factors that influence proxy reports during bereavement. In any prospective research on comfort at the end of life, patient, caregiver and staff input will be required. Definitions of comfort (physical, emotional, social) will need to be explored.

\section{Conclusions}

For practice and for service planning, this study supports a measurable benefit from SPCS involvement at a population level with higher levels of comfort in the last 2 weeks of life in people who accessed services. However, the challenge is to ensure that people who are perceived to be 'uncomfortable' and 'very uncomfortable' have systematic attempts to improve the quality of their care given the high prevalence of discomfort irrespective of SPCS utilisation. This requires all clinicians involved in end-of-life care to continue to explore ways to adequately identify that a person is dying and providing attention to optimising comfort until death. Such findings also require health service planners to improve ways of delivering care to all people with complex needs facing a life-limiting illness.

Competing interests The authors declare no competing interests.

Funding Daw House Hospice Foundation, Daw Park, South Australia, Australia.

Open Access This article is distributed under the terms of the Creative Commons Attribution Noncommercial License which permits any noncommercial use, distribution, and reproduction in any medium, provided the original author(s) and source are credited.

\section{References}

1. Addington-Hall J, Altmann D (2000) Which terminally ill cancer patients in the United Kingdom receive care from community specialist palliative care nurses? J Adv Nurs 32(4):799-806

2. Addington-Hall J, McPherson C (2001) After-death interviews with surrogates/bereaved family members: some issues of validity. J Pain Symptom Manage 22(3):784-790

3. Ahmed N, Bestall JC, Ahmedzai SH, Payne SA, Clark D, Noble B (2004) Systematic review of the problems and issues of accessing specialist palliative care by patients, carers and health and social care professionals. Palliat Med 18(6):525-542

4. Ahmedzai S, Morton A, Reid JT, Stevenson RD (1988) Quality of death from lung cancer: patients' reports and relatives' retrospective opinions. In: Watson $\mathrm{M}$, Greer S, Thomas $\mathrm{C}$ (eds) Psychosocial oncology. Pergamon, Oxford, p 187-192

5. Anderson JA (1984) Regression and ordered categorical variables. J R Stat Soc B 46:1-30

6. Anon (October 1999) State of the Nation 1998. Report of the National Census of Palliative Care Services. Palliative Care Australia, Canberra

7. Anon (2002) National cancer control programmes. Policies and managerial guidelines. World Health Organisation, Geneva

8. Anon (released 22/03/07, accessed 23/04/07) Australian Bureau of Statistics. Latest issue 3101.0-Australian Demographic Statistics. At www.abs.gov.au/ausstats/abs@.nsf

9. Brumley RD, Euguidanos S, Cherin DA (2003) Effectiveness of a home-based palliative care program for end-of-life. J Palliat Med $6(5): 715-724$ 
10. Cartwright A, Seale C (1990) The natural history of a survey: an account of the methodological issues encountered in a study of life before death. King Edward's Hospital Fund, London, p 111-118

11. Christianson SA (1992) Emotional stress and eyewitness memory: a critical review. Psychol Bull 112:284-309

12. Constantini M, Higginson IJ, Bon L, Orengo MA, Garrone E, Henriquet F, Bruzzi P (2003) Effect of palliative home care team on hospital admissions among patients with advanced cancer. Palliat Med 17(4):315-321

13. Currow DC, Abernethy AP, Fazekas BS (2004) Specialist palliative care needs of whole populations: a feasibility study using a novel approach. Palliat Med 18:239-247

14. Currow DC, Agar M, Shelby-James T, Abernethy A (2008) Access to palliative care services. Does lack of access equate with unmet need? Palliat Med 22(1):43-50

15. Eagar K, Gordon R, Green J, Smith M (2004) An Australian casemix classification for palliative care: lessons and policy implications of a national study. Palliat Med 18:227-233

16. Field D, Douglas C, Jagger C, Dand P (1995) Terminal illness: views of patients and their lay carers. Palliat Med 9:45-54

17. Finlay IG, Higginson DM, Goodwin AM, Cook AM, Edwards AGK, Hood K, Douglas HR, Normand CE (2002) Palliative care in hospital, hospice, at home: results from a systematic review. Ann Oncol Suppl 4:257-264

18. Goodwin DM, Higginson IJ, Edwards AGK, Finlay IG, Cook AM, Hood K, Douglas H, Normand CE (2002) An evaluation of systematic reviews of palliative care services. J Palliat Care 18(2):77-83

19. Harding R, Karus D, Easterbrook P, Raveis VH, Higginson IJ, Marconi K (2005) Does palliative care improve outcomes for patients with HIV/AIDS? A systematic review of the evidence. Sex Transm Infect 81:5-14

20. Hearn J, Higginson IJ (1998) Do specialist palliative care teams improve outcomes for cancer patients? A systematic literature review. Palliat Med 12:317-332

21. Heyland DK, Dodek P, Rocker G, Groll D, Gafni A, Pichora D, Shortt S, Tranmer J, Lazar N, Kutsogiannis J, Lam M, Canadian End of Life Network (CARENET) (2006) What matters most in end-of-life care: perceptions of seriously ill patients and their family members. CMAJ 174(5):627-633

22. Higginson I, Priest P, McCarthy M (1994) Are bereaved family members a valid proxy for a patient's assessment of dying? Soc Sci Med 38(4):553-557

23. Higginson IJ, Jarman B, Astin P, Dolan S (1999) Do social factors affect where patients die: an analysis of 10 years of cancer deaths in England. J Public Health Med 21:22-28

24. Higginson IJ, Finlay I, Goodwin DM, Cook AM, Hood K, Edwards AGK, Douglas H, Norman CE (2002) Do hospital-based palliative care teams improve care for patients of families at the end of life? J Pain Symptom Manage 23(2):96-106

25. Higginson IJ, Finlay IG, Goodwin DM, Hood K, Edwards AGK, Cook A, Douglas H, Normand CE (2003) Is there evidence that palliative care teams alter end-of-life experiences of patients and their caregivers? J Pain Symptom Manage 25(2):150-168

26. Hillier JB, Williams A, Oldham J (2003) Hospital based palliative care teams improve the symptoms of cancer patients. Palliat Med 17(6):498-502

27. Hinton J (1996) How reliable are relatives' retrospective reports of terminal illness? Patients' and relatives' accounts compared. Soc Sci Med 43(8):1229-1236

28. Hughes SL, Cummings J, Weaver F, Manhein L, Braun B, Conrad K (1992) A randomized trial of the cost effectiveness of VA hospital-based home care for the terminally ill. Health Serv Res 26 (6):801-817

29. Jacobsen PB, Donovan KA, Trask PC, Fleishman SB, Zabora J, Baker F, Holland JC (2005) Screening foe psychologic distress in ambulatory cancer patients. A multicentre evaluation of the distress thermometer. Cancer 103:1494-1502

30. Kane RL, Bernstein L, Wales J, Leibowitz A, Kaplan S (1984) A randomized controlled trial of hospice care. Lancet 323 (8382):890-894

31. Klinkenberg M, Smit JH, Deeg DJH, Willems DL, OnwuteakaPhilipsen BD, van der Wal G (2003) Proxy reporting in after death interviews: the use of proxy respondents in retrospective assessment of chronic diseases and symptom burden in the terminal phase of life. Palliat Med 17(2):191-201

32. Kristjanson LJ, Nikoletti S, Porock D, Smith M, Lobchuk M, Pedler P (1998) Congruence between patients' and family caregivers' perceptions of symptom distress in patients with terminal cancer. J Palliat Care 14(3):24-32

33. Kutner JS, Bryant LL, Beaty BL, Fairclough DL (2006) Symptom distress and quality-of-life assessment at end of life: the role of proxy response. J Pain Symptom Manage 32(4):300-310

34. Lobchuk MM, Degner LF (2002) Symptom experiences: perceptual accuracy between advanced-stage cancer patients and family caregivers in the home care setting. J Clin Oncol 20(16):3495-3507

35. Lobchuk MM, Kristjanson L, Degner L, Blood P, Sloan JA (1997) Perceptions of symptom distress in lung cancer patients: I. Congruence between patients and primary family caregivers. J Pain Symptom Manage 14(3):136-146

36. Lynn J, Teno JM, Phillips RS, Wu AW, Desbiens N, Harrold J, Claessens MT, Wegner N, Kreling B, Connors AF (1997) Perceptions of family members of the dying experience of older and seriously ill patients. SUPPORT investigators. Study to Understand Prognoses and Preferences for Outcomes and Risks of Treatment. Ann Intern Med 126:97-106

37. McMillan SC, Moody LE (2003) Hospice patient and caregiver congruence in reporting patients' symptom intensity. Cancer Nurs 26(2):113-118

38. McNamara B, Rosenwax L, Holman C (2006) A method for defining and estimating the palliative care population. J Pain Symptom Manage 32:5-12

39. McPherson CJ, Addington-Hall JM (2003) Judging the quality of care at end of life: can proxies provide reliable information. Soc Sci Med 56:95-109

40. McPherson CJ, Addington-Hall JM (2004) Evaluating palliative care: bereaved family members' evaluations of patients' pain, anxiety and depression. J Pain Symptom Manage 28(2):104-114

41. McPherson CJ, Addington-Hall JM (2004) How do proxies' perceptions of patients' pain, anxiety and depression change during the bereavement period? J Palliat Care 20(1):12-19

42. Miaskowski C, Zimmer EF, Barrett KM, Dibble SL, Wallhagen M (1997) Differences in patients' and family caregivers' perceptions of the pain experience influence patient and caregiver outcomes. Pain 72(1-2):217-226

43. Miller SC, Mor V, Teno J (2003) Hospice enrolment and pain assessment and management in nursing homes. J Pain Symptom Manage 26(3):791-799

44. Miller SC, Mor V, Wu N, Gonzalo P, Lapane K (2002) Does receipt of hospice care in nursing homes improve the management of pain at the end of life? J Am Geriatr Soc 50:507-515

45. Milne DJ, Mulder LL, Beelen HC, Schofield P, Kempen GIJM, Aranda S (2006) Patients' self report and family caregivers' perception of quality of life in patients with advanced cancer: how do they compare? Eur J Cancer Care 15(2):125-132

46. Murillo M, Holland JC (2004) Clinical practice guidelines for the management of psychosocial distress at the end of life. Palliat Support Care 2(1):65-67

47. Redinbaugh EM, Baum A, DeMoss C, Fello M, Arnold R (2002) Factors associated with the accuracy of family caregiver estimates of patient pain. J Pain Symptom Manage 23(1):31-38 
48. Singer PA, Martin DK, Kelner M (1999) Quality end-of-life care: patients' perspectives. JAMA 281(2):163-168

49. South Australian Health Omnibus Survey. http://www.dh.sa.gov. au/pehs/PROS/HOS.html

50. Spiller JA, Alexander DA (1993) Domiciliary care: a comparison of views of terminally ill patients and their family caregivers. Palliat Med 7:109-115

51. Steinhauser KE, Clipp EC, McNeilly M, Christakis NA, McIntyre LM, Tulsky JA (2000) In search of a good death: observations of patients, families and providers. Ann Intern Med 132:825-832

52. Taylor Jr DH, Ostermann J, Van Houtven CH, Tulsky JA, Steinhauser K (2007) What length of hospice use maximizes reduction in medical expenditures near death in the US Medicare program? Soc Sci Med 65(7):1466-1478

53. Teno JM, Casey VA, Welch LC, Edgman-Levitan S (2001) Patient-focused, family-centred end-of-life medical care: views of the guidelines and bereaved family members. J Pain Symptom Manage 22(3):738-751

54. Teno JM, Clarridge BR, Casey V, Welch LC, Wetle T, Sheild R, Mor V (2004) Family perspectives on end-of-life care at the last place of care. JAMA 291(1):88-93

55. Wallston KA, Burger C, Smith RA, Baugher RJ (1988) Comparing the quality of death for hospice and non-hospice cancer patients. Med Care 26(2):177-182 